\title{
Does lactate clearance prognosticates outcomes in ECMO therapy: a retrospective observational study
}

\author{
Ibrahim Mungan * (D), Dilek Kazancı, Şerife Bektaş, Derya Ademoglu and Sema Turan
}

\begin{abstract}
Background: ECMO support is a final treatment modality for patients in the refractory cardiogenic arrest and postcardiotomy cardiogenic shock with an utmost importance. Eventhough it is linked to high mortality, its usage gains popularity worldwide. We assessed the fluctuation of lactate levels and the clearance of lactate during the ECMO therapy and its prognostic role on mortality.

Methods: Data were gathered on all patients receiving ECMO therapy longer than $48 \mathrm{~h}$ between January 2015 and December 2017 retrospectively. Blood lactate had been recorded before ECMO implantation and at specific time points during ECMO support as a routine procedure. In this study, the Lactate clearance at specific time points (Lactate clearance-1) and the duration that lactate cleared more than 10\% of the initial lactate level (Lactate clearance-2) was measured. Statistical analysis included Mann Whitney U-test and ROC-curves to predict 30-day mortality.

Results: Fourty-eight patients underwent ECMO therapy for refractory cardiogenic shock resulting in $70.8 \%$ mortality. The lactate levels before and after ECMO therapy as well as the dynamic changes were significantly correlated with mortality variable. With AUC calculation, $L C-2$ has a strong discrimination (AUC $=0.97$ ) on 30-day survivors and nonsurvivors. $L A E-L B E(A \cup C=0.785)$, L48-LBE (AUC $=0.706$ ) showed moderate predictive power on 30-day mortality.

Conclusions: Changes in lactate levels after ECMO implantation is an important tool to assess effective circulatory support and it is found superior to single lactate measurements as a prognostic sign of mortality in our study. Based on our results, an early insertion of ECMO before lactate gets high was suggested. Serial changes on lactate levels and calculation of its clearance may be superior to single lactate on both effective circulatory support and as prognostic prediction. LC-2 showed a strong discrimination on 30-day mortality.
\end{abstract}

Keywords: Extracorporeal membrane oxygenation, Lactate, Clearance

\section{Background}

During cardiogenic shock and cardiac arrest, oxygen supply and blood perfusion are critically reduced; these deteriorations can be corrected by extracorporeal mechanical life support in principle [1]. Extracorporeal membrane oxygenation (ECMO) is one of the methods used to provide temporary mechanical support of the cardiac and/or pulmonary function. It has two types of usage and Veno-arterial-ECMO (V-A ECMO) decreases preload and increases the aortic flow and end-organ

\footnotetext{
* Correspondence: imungan@gmail.com

Department of Intensive Care Unit, Turkey Advanced Speciality Education and Research Hospital, Altındag, Ankara, Turkey
}

perfusion. In this way, ECMO can safeguard the myocardium which ensures better survival [2]. The other type [Veno-venous ECMO (V-V ECMO)] is mainly used with lung-protective ventilation for the treatment of acute respiratory distress syndrome and respiratory failure without cardiac failure [1]. Cardiac surgery-as in post-cardiotomy low cardiac output syndrome-, acute myocardial infarction, decompensated cardiomyopathy, Takotsubo syndrome, or acute myocarditis may be complicated by severe myocardial dysfunction ensuing in cardiogenic shock and consequently requiring ECMO as a treatment option [3].

(C) The Author(s). 2018 Open Access This article is distributed under the terms of the Creative Commons Attribution 4.0 International License (http://creativecommons.org/licenses/by/4.0/), which permits unrestricted use, distribution, and reproduction in any medium, provided you give appropriate credit to the original author(s) and the source, provide a link to the Creative Commons license, and indicate if changes were made. The Creative Commons Public Domain Dedication waiver (http://creativecommons.org/publicdomain/zero/1.0/) applies to the data made available in this article, unless otherwise stated. 
Lactate is a metabolic product of anaerobic glycolysis and may express inadequate oxygen delivery. It is also suggested to be an indicator of tissue perfusion affected not only by macrocirculation but also by microcirculation [4]. After cardiac arrest or cardiac surgery, discordance between $\mathrm{O}_{2}$ demand and supply causes an increase in lactate level, which reflects the imbalance between production and clearance of lactate. This increment in lactate level has been associated with poor prognosis and mortality [5].

Lactate is mainly cleared by the liver, skeletal and cardiac myocytes, and proximal tubule kidney cells. It is claimed that the cause of hyperlactatemia in patients who get stabilized via ECMO support is the decrease in lactate clearance rather than increased production of lactate as in sepsis without hemodynamic instability [6].

Even recent reports concluded that serial lactate measurements and lactate clearance are more reliable for risk stratification than absolute levels of lactate [7]. In this study, we hypothesized that the lactate clearance in different time points (LC-1) or the duration to clear more than $10 \%$ of original lactate (LC-2) may show a better correlation with clinical outcomes on ECMO support after cardiac surgery or cardiogenic shock.

\section{Methods}

This retrospective analysis was performed with all consecutive patients receiving a V-A ECMO for either refractory cardiogenic shock or cardiac arrest between January 2015 and December 2017 in a tertiary state hospital. In this study, only patients undergoing at least $48 \mathrm{~h}$ of ECMO therapy were included to allow assessment of serial lactate measurements during ECMO support. Patients undergoing V-V ECMO support and patients requiring ECMO support for respiratory failure and patients dead before $48 \mathrm{~h}$ were excluded from the analysis. An extra formal consent other than the patients had given prior to the admission to intensive care unit (ICU) as a routine procedure, was not required for the current study because it was a case-control medical record review. Since our study was in the category of non-interventional clinical research with its retrospective structure, no ethics committee approval was applied. This situation is in line with the National Code of Clinical Research which was published on 13th April 2013 [8].

This study adhered to the principles in accordance with the Helsinki Declaration of 1975, as revised in 2008.

\section{ECMO indication}

Intraoperative ECMO support indications were either failure to wean cardiopulmonary bypass due to circulatory instability or hemodynamic impairment after weaning. Postoperative ECMO support indications were refractory postcardiotomy cardiogenic shock and decompensated cardiomyopathy in spite of optimized inotropic therapy and supportive measures (e.g. intra-aortic balloon pump). This proposed situation was defined by systolic arterial hypotension $(<80 \mathrm{mmHg})$, signs of end-organ failure (urine output $<0.5 \mathrm{ml} / \mathrm{h} / \mathrm{kg}$ or need for dialysis as renal failure; persistent elevated lactate levels $>3 \mathrm{mmol} / \mathrm{l}$, central venous oxygen saturation $\left(\mathrm{ScvO}_{2}\right)<50 \%$ as respiratory failure) and low cardiac output (cardiac index $<1.8 \mathrm{l} / \mathrm{min} / \mathrm{m}^{2}$ Body surface area). In patients presenting cardiogenic shock as in cardiac arrest, without previous cardiac surgery, identical clinical criteria were applied for postoperative ECMO indications. In patients under resuscitation, the decision to implant ECMO was made by the participating cardiac surgeon. The improvement in respiratory functions, decreasing trend of lactate levels and improved hemodynamics were the criteria for weaning off ECMO support.

\section{Data acquisition}

All clinical variables of patients, necessitating ECMO support were retrospectively recorded in our institutional database. Renal failure was defined as the presence of oliguria $(<0.5 \mathrm{ml} / \mathrm{kg} / \mathrm{h})$, the optimisation of fluid loading and a doubling of post-ECMO creatinine values with the need for renal replacement therapy (hemodialysis or filtration). This definition was corresponding to Stages 2 and 3 according to the Kidney Disease: Improving Global Outcomes (KDIGO) definition of acute kidney injury (AKI) [9]. The neurological complication was defined as the presence of clinical or radiological evidence for a neurological deficit or defect, e.g. stroke, severe cerebral bleeding or severe cerebral oedema. Mortality as a variable in this study was described as death from any cause occurring within 30-days after ECMO implantation.

Blood lactate values were measured by arterial blood gas analysis on ICU hourly in the first hours after ECMO implantation until stable conditions were achieved. Later on, lactate values were determined in a two-hour interval. There are so many conflicts in the literature defining lactate clearance to assess its predictive power and we chose two defining models as lactate clearance level. Both of them based on the lactate value before ECMO implantation. Lactate clearance-1 (LC-1) was calculated by the following equation: Lactate clearance (time point) = lactate value before ECMO implantation - lactate value at the specific time point. The other definition of the lactate clearance [lactate clearance-2 (LC-2)] was duration between ECMO implantation and time point that lactate cleared more than $10 \%$ of the initial lactate level. 


\section{Statistical analysis}

Statistical analysis was performed using SPSS version 20.0 for Windows (SPSS Inc., Chicago, IL, USA) and MedCalc 15.8 software (MedCalc, Ostend, Belgium). Data were analyzed, and the continuous variables were reported as mean \pm standard deviation (SD), and nominal variables were reported as total number and percentages.

Variables were first evaluated by One-Sample Kolmogorov-Smirnov test as a normality test to choose the type of statistical tests -parametric or non-parametric test-, and the results showed that asymp. Sig. (2-tailed) levels $\leq 0.05$ so we decided to use non-parametric tests. For statistical analysis, correlations between variables were evaluated for significance by using the Spearman's rho test. Categorical variables were evaluated by the MannWhitney $\mathrm{U}$ test of contingency. In all analyses, a ' $p$ ' value of less than 0.05 was considered statistically significant.

Apart from this, we established a receiver operating characteristic (ROC) curve to evaluate the ability of LC-1 and LC-2 to predict 30-day mortality. In this analysis, ROC-Area Under Curve (AUC) was calculated to quantify the accuracy of the predictive model. AUC value $>0.75$ was appraised as satisfactory, AUC value $>$ 0.8 was appraised as well, and AUC value $>0.9$ was appraised as very good.

\section{Results}

From January 2015 to December 2017, 59 patients underwent V-A ECMO implantation in our hospital for either post-cardiotomy refractory cardiogenic shock, decompensated cardiomyopathy or cardiac arrest. Only $81.3 \%(48 / 59)$ of these patients had at least $48 \mathrm{~h}$ of ECMO support and fulfill the inclusion criteria of our study (Fig. 1). Nine patients were successfully disconnected from ECMO support and seven patients were switched to the left ventricular assist device (LVAD). Thirty-day mortality in the study cohort was 70.8\% (34/ 48), while $18.6 \%(11 / 59)$ of patients with ECMO support less than $48 \mathrm{~h}$ died, resulting in a cumulative 30-day mortality of $76.2 \%(45 / 59)$ in this time period. In-hospital mortality for the study population cohort was $83.3 \%$ (40/48) with cardiac death $(31 / 48$; $64.5 \%)$ being the most frequent cause of death. Other causes of death were sepsis $(3 / 48 ; 6.3 \%)$, mesenteric ischemia (1/ $48 ; 2.1 \%)$, cerebral death $(2 / 48 ; 4.2 \%)$, untreatable bleeding $(2 / 48 ; 4.2 \%)$ and other causes not assigned to the categories mentioned before $(1 / 48 ; 2.1 \%)$. Demographic data and clinical scenario before ECMO implantation of the included patients are shown in Table 1.

The survivors regarding 30-day mortality were younger. Other demographic variables were similar and not significant statistically. The clinical situation (e.g.decompensated cardiomyopathy, etc.) before ECMO implantation had no impact on 30-day mortality, length of stay (LOS) in the hospital or in the ICU. ECMO data of the complete patient cohort with ECMO support more than $48 \mathrm{~h}$ as well as complications and outcomes after ECMO support are summarized in Table 2.

ECMO duration is longer for the survivors compared to non-the survivors yet this was expected as therapy continues in the survivor group. ECMO implantations were done as extracorporeal cardiopulmonary resuscitation (eCPR) refractory to conventional CPR in $31.3 \%(n=15)$ of the cases. ECMO implantations were performed in the ICU in $62.5 \%(n=30)$ of the study cases. ECMO implantation in the ICU and eCPR usage as a variable had no significant relation statistically with mortality. The most common ECMO-related complications were severe bleeding (8.3\%) and limb ischemia (8.3\%), particularly in peripheral ECMO implantation.

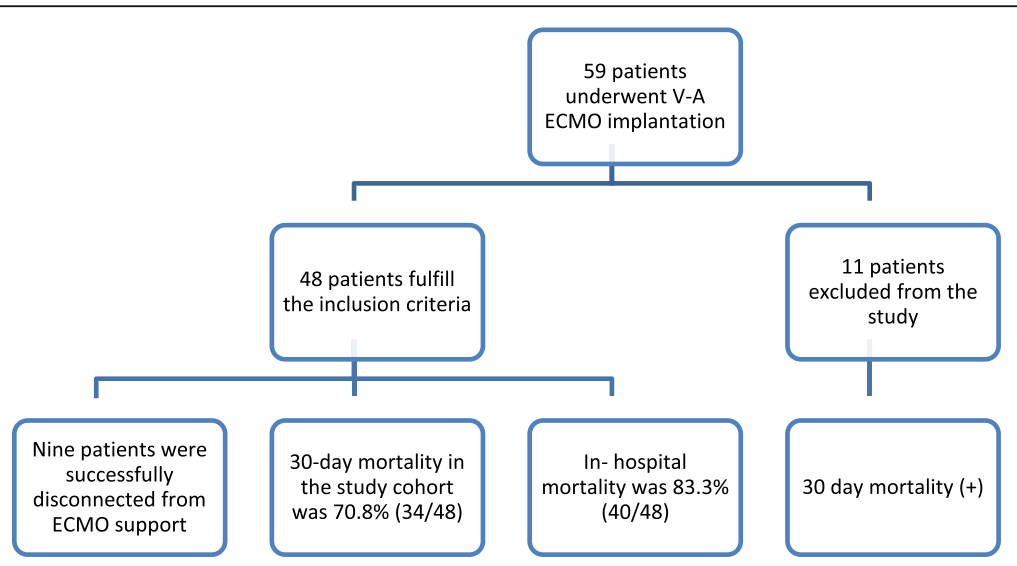

Fig. 1 The flowchart describing the initial and study population 
Table 1 Demographic data and clinical scenario before ECMO implantation of patients undergoing ECMO for cardiogenic shock

\begin{tabular}{lllll}
\hline & All $(n=48)$ & Survivors $(n=14)$ & Non-survivors $(n=34)$ & $p$-value \\
\hline Age (Years) & $54 \pm 13$ & $47 \pm 11$ & $57 \pm 12$ & 0.006 \\
Gender (Male) & $31(64.6 \%)$ & $10(71.4 \%)$ & $21(61.8 \%)$ & \\
ECMO support indications & & & & \\
$\quad$ Postcardiotomy cardiogenic shock & $26(54.2 \%)$ & $8(57.1 \%)$ & $18(52.9 \%)$ & $11(32.4 \%)$ \\
Cardiac arrest & $15(31.3 \%)$ & $4(28.6 \%)$ & $5(14.7 \%)$ & 0.823 \\
Decompensated cardiomyopathy & $7(14.6 \%)$ & $2(14.3 \%)$ & \\
\hline
\end{tabular}

Subgroups (The survivors versus Non-the survivors) refer to 30-day mortality. $p$-values calculated for comparison of the survivors versus non-the survivors by statistical analysis

Data are mean \pm SD or $n(\%)$

*Determined by Mann-Whitney U test or Spearman's rho test

Abbreviations: ECMO extracorporeal membrane oxygenation

If patients were hemodynamically stable and adequately oxygenated, they were considered for ECMO weaning when the flow rate was $1 \mathrm{l} / \mathrm{min} / \mathrm{m}^{2}$ for $4 \mathrm{~h}$. Survival of more than $12 \mathrm{~h}$ after discontinuation of ECMO support was defining successful ECMO weaning and accomplished only in nine patients (18.8\%).

In the survivor group of patients with ECMO support, the LOS in-hospital $(38.79 \pm 20.3$ days vs $7.0 \pm 4.9$ days $)$ and LOS in ICU ( $21.5 \pm 17.0$ days vs $6.9 \pm 4.5$ days $)$ were significantly longer. In this study, $62.5 \%(n=30)$ of ECMO support patients developed acute renal failure and $31.3 \%$ of them had neurological complications.

\section{Blood lactate}

Lactate levels were elevated before ECMO implantation $(10.9 \pm 5.4 \mathrm{mmol} / \mathrm{l})$ and there was a significant difference depending on 30-day mortality (the survivors vs. non-the survivors: $7.6 \pm 2.7 \mathrm{mmol} / \mathrm{l}$ vs $12.3 \pm 5.7 \mathrm{mmol} / \mathrm{l}$; $p=0.008$ ). All patients presented a $10 \%$ decrease in basal lactate levels but the duration of this period was significantly different between groups. Even the lactate value $1 \mathrm{~h}$ after ECMO support was different statistically and predictive concerning 30-day mortality (the survivors vs. non-the survivors: $6.4 \pm 2.6 \mathrm{mmol} / \mathrm{l}$ vs $11.5 \pm 5.6 \mathrm{mmol} / \mathrm{l}$; $p=0.003)$. However, the significance of the lactate

Table 2 Complications and outcomes after ECMO therapy

\begin{tabular}{|c|c|c|c|c|}
\hline & All $(n=48)$ & Survivors $(n=14)$ & Non-survivors $(n=34)$ & $p$-value ${ }^{*}$ \\
\hline Postoperative ECMO & $33(68.7 \%)$ & $10(71.4 \%)$ & $23(67.6 \%)$ & 0.802 \\
\hline ECMO during CPR & $15(31.3 \%)$ & $4(28.6 \%)$ & $11(32.4 \%)$ & \\
\hline Central cannulation & $13(27.0 \%)$ & $3(21.4 \%)$ & $10(29.4 \%)$ & 0.581 \\
\hline ECMO implantation at ICU & $30(62.5 \%)$ & $8(57.1 \%)$ & $22(64.7 \%)$ & 0.632 \\
\hline \multicolumn{5}{|l|}{ ECMO related complications } \\
\hline Severe Bleeding & $4(8.3 \%)$ & $1(7.1 \%)$ & $3(8.8 \%)$ & 0.730 \\
\hline Limb ischemia & $4(8.3 \%)$ & $1(7.1 \%)$ & $3(8.8 \%)$ & \\
\hline Intracardiac thrombus & $1(2.1 \%)$ & $1(7.1 \%)$ & $0(0 \%)$ & \\
\hline Renal failure with dialysis & $30(62.5 \%)$ & $6(42.9 \%)$ & $24(70.6 \%)$ & 0.074 \\
\hline Neurological complication & $15(31.3 \%)$ & $5(35.7 \%)$ & $10(29.4 \%)$ & 0.676 \\
\hline ECMO duration (days) & $8.5 \pm 9.4$ & $14.21 \pm 15.0$ & $6.2 \pm 4.1$ & 0.131 \\
\hline LOS in-hospital (days) & $16.3 \pm 18.5$ & $38.79 \pm 20.3$ & $7.0 \pm 4.9$ & $<0.001$ \\
\hline LOS in-ICU (days) & $11.1 \pm 11.8$ & $21.5 \pm 17.0$ & $6.9 \pm 4.5$ & $<0.001$ \\
\hline Successful ECMO weaning & $9(18 \%)$ & $9(64.3 \%)$ & $0(0 \%)$ & $<0.001$ \\
\hline LVAD & $7(14.6 \%)$ & $1(7.1 \%)$ & $6(17.6 \%)$ & 0.359 \\
\hline 30-day mortality & $34(70.8 \%)$ & & & \\
\hline In-hospital mortality & $40(83.3 \%)$ & & & \\
\hline
\end{tabular}

Subgroups (The survivors versus Non-the survivors) refer to 30-day mortality. $p$-values calculated for comparison of the survivors versus non-the survivors by statistical analysis

Data are mean \pm SD or $n(\%)$

"Determined by Mann-Whitney $\mathrm{U}$ test or Spearman's rho test

Abbreviations: ECMO extracorporeal membrane oxygenation, CPR cardiopulmonary resuscitation, ICU intensive care unit, LOS length of stay, LVAD left ventricular assist device 
difference considering post-ECMO and pre-ECMO lactate values was more prominent $(-1.2 \pm 0.6$ vs $-0.9 \pm$ $0.8 ; p=0.002)$. Thus, we decided to make assumptions with lactate differences (LC-1, and LC-2) rather than the absolute lactate value. Nevertheless, we summarize lactate values and LC-2 in Fig. 2 and compare them according to the mortality factor. It was obvious that the difference in LC-2 was the most remarkable one among the variables.

In Table 3, lactate levels, LC-1 at specific time points and LC-2 were compared depending on 30-day mortality. In addition, the predictive value of lactate level, LC-1 for specific time points and LC-2 were assessed by using ROC curve analysis (Fig. 3). It is clearly seen that LC-2 (as the duration for lactate clearance of more than $10 \%$ of initial level) had a stronger predictive power. AUC ROC values with 95\% CI were 0.97 for LC-2, 0.706 for LC-1 $(48 \mathrm{~h})$, and 0.785 for LC-1 $(1 \mathrm{~h})$ respectively. Apart from this, LC-2 was related to and had predictive power with LOS in ICU more than 5 days (Fig. 4).

\section{Discussion}

ECMO is claimed to be a very effective tool for providing and advancing systemic circulation and provide gas exchange. In cardiogenic shock and cardiac arrest, it is used as a mechanical support mostly. The goal of the ECMO usage is myocardial rest while protecting end-organ perfusion and supporting good neurologic function after the course [1]. The mortality rate is reported between 60 and 80\% [10] and our 30-day mortality rate in cardiogenic shock with ECMO support is similar (70.8\%).

The imbalance between production and clearance of lactate causes higher lactate levels and LC may prognosticate the mortality in patients on extracorporeal circulatory support. It has also been correlated with survival, in post-cardiac arrest, after the return of spontaneous circulation with the help of ECMO [6]. Li et al. [5] noticed that fluctuations in lactate values following the ECMO implantation can presage in-hospital mortality in post-cardiac surgery patients. Hence the improvement in LC and the decreasing trend of lactate levels may be considered as a sign of improvement in perfusion and oxygenation during eCPR, in patients with refractory cardiac arrest on ECMO support [5]. Serial lactate measurements over time or lactate clearance have been reported to be clinically more reliable than absolute values of lactate, as a surrogate for the magnitude and duration of global tissue hypoxia, for risk stratification in different pathologic conditions ranging from sepsis to trauma $[1,6,11]$.

In our patients, we measured lactate levels and calculated LC-1 at 6, 24 and $48 \mathrm{~h}$ after initiation of ECMO. We also measured LC-2 (time) as defined in the material method section. LC-1 at $48 \mathrm{~h}$ and LC-2 were found significantly related to mortality while LC-1 at 6 and $24 \mathrm{~h}$ had no relation. Especially, the LC-2 correlation was significant statistically with greater strength $(p<0.001)$. With AUC calculation, $\mathrm{LC}-2$ has a strong discrimination

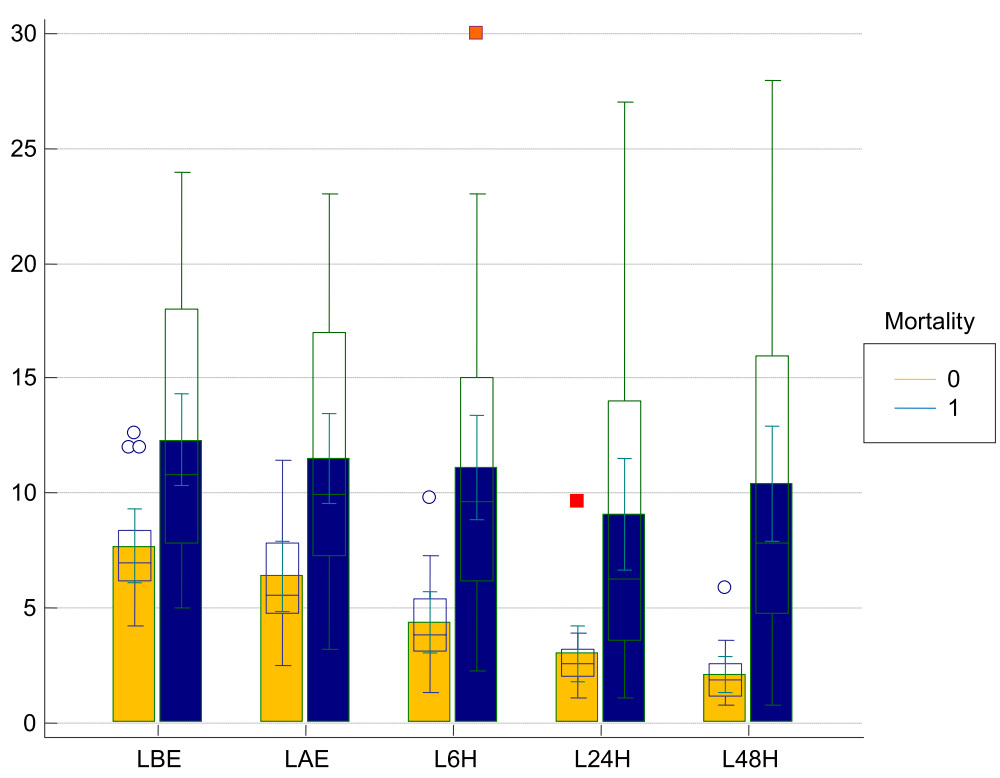

Fig. 2 Changes in blood lactate levels detected on different time points depending on mortality. Mortality 1, represents the nonthe survivor group while mortality 0 represents the survivor group. LBE, Lactate level pre-ECMO (mmol/l); LAE, Lactate level post-ECMO (mmol/l); L6 h, Lactate level $6 \mathrm{~h}$ after ECMO implantation; L24 h, Lactate level $24 \mathrm{~h}$ after ECMO implantation; L48 h, Lactate level $48 \mathrm{~h}$ after ECMO implantation 
Table 3 Lactate levels, lactate clearance-1 at specific time points and lactate clearance-2 were compared

\begin{tabular}{|c|c|c|c|c|}
\hline & All $(n=48)$ & Survivors $(n=14)$ & Non-survivors $(n=34)$ & $p$-value \\
\hline LL pre-ECMO $(\mathrm{mmol} / \mathrm{l})$ & $10.9 \pm 5.4$ & $7.6 \pm 2.7$ & $12.3 \pm 5.7$ & 0.008 \\
\hline LL post-ECMO $(\mathrm{mmol} / \mathrm{l})$ & $10.0 \pm 5.4$ & $6.4 \pm 2.6$ & $11.5 \pm 5.6$ & 0.003 \\
\hline LL postECMO- LL preECMO (mmol/l) & $-0.9 \pm 0.8$ & $-1.2 \pm 0.6$ & $-0.9 \pm 0.8$ & 0.002 \\
\hline LC-1 6 h (mmol/l) & $-1.8 \pm 4.4$ & $-3.2 \pm 1.1$ & $-1.8 \pm 4.4$ & 0.017 \\
\hline LC-1 24 h (mmol/l) & $-3.6 \pm 5.6$ & $-4.6 \pm 2.2$ & $-3.6 \pm 5.6$ & 0.634 \\
\hline LC-1 $48 \mathrm{~h}(\mathrm{mmol} / \mathrm{l})$ & $-2.9 \pm 6.2$ & $-5.5 \pm 2.6$ & $-2.9 \pm 6.2$ & 0.023 \\
\hline LC-2 (hours) & $7.0 \pm 6.1$ & $1.3 \pm 1.3$ & $9.4 \pm 5.8$ & $<0.001$ \\
\hline
\end{tabular}

Subgroups (The survivors versus Non-the survivors) refer to 30-day mortality. $p$-values calculated for comparison of the survivors versus non-the survivors by statistical analysis

Data are mean \pm SD or $n(\%)$

*Determined by Mann-Whitney U test or Spearman's rho test

Abbreviations: ECMO extracorporeal membrane oxygenation, $L L$ lactate level at specific time, $L C-1$ lactate clearance at specific time, $L C-2$ the duration between ECMO implantation time and time point that Lactate cleared more than $10 \%$ of the initial level

$(\mathrm{AUC}=0.97)$ on 30 -day the survivors and nonthe survivors. Lactate level post-ECMO (mmol/l) (LAE) - Lactate level pre-ECMO $(\mathrm{mmol} / \mathrm{l})(\mathrm{LBE})(\mathrm{AUC}=0.785)$, Lactate level $48 \mathrm{~h}$ after ECMO implantation (L48 h) -LBE (AUC $=0.706$ ) showed moderate predictive power on 30-day mortality. Due to the fact that in 13 patients, ECMO support could not achieve to decrease lactate value below the level of $4 \mathrm{mmol} / \mathrm{l}$, this cutoff value as a variable could not be used for mortality prediction model in this study. This lactate level is important because it is claimed as a predictor of death in some studies $[12,13]$.

Even in some studies, it is postulated that ECMO decannulation is proper when the LC remained within $10 \%$ of baseline $[6,14]$. However, our study was designed in a retrospective manner so we could only check LC for mortality prediction and correlation. It is clearly shown that the dynamic changes of lactate levels are related to mortality and LOS in ICU more than 5 days.

In the present study, lactate levels were elevated before ECMO implantation and there was a significant difference depending on 30 -day mortality $(p=0.008)$. This correlation implies that early support by ECMO probably avoids progression to multiorgan failure by improving tissue perfusion.

\section{Limitations}

There are some limitations related to this study that need to be acknowledged. First, the retrospective nature is a major limitation of this analysis. Secondly, the small sample size and limited data are restricting our

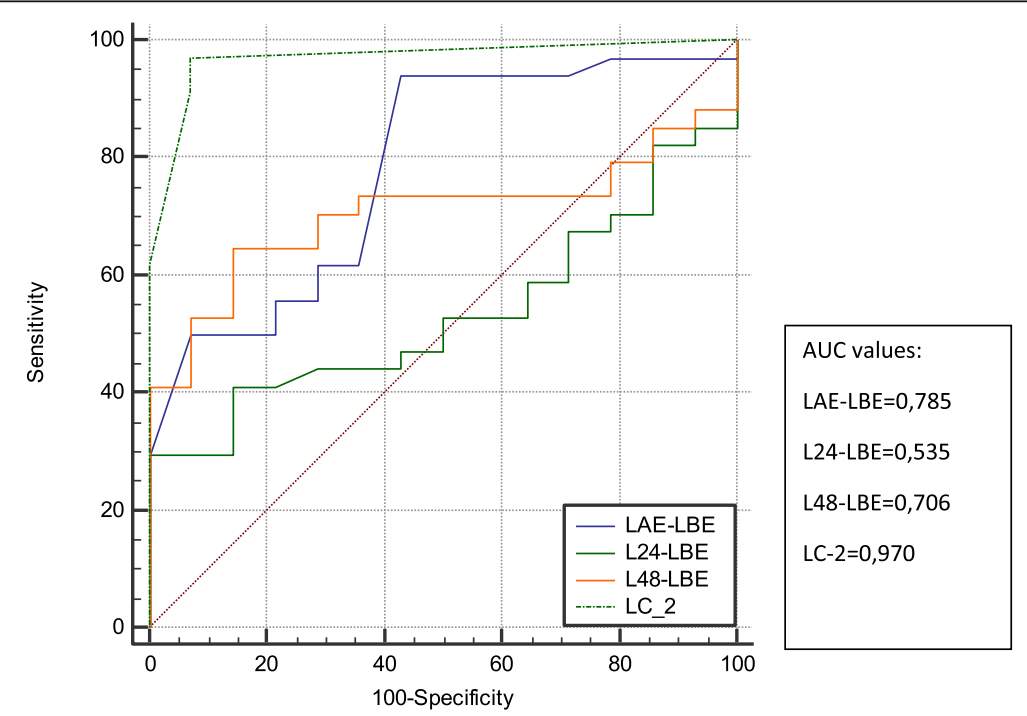

Fig. 3 ROC curves to demonstrate the power of predictively of LC-1 at each time point and LC-2 on 30-day mortality. ROC, receiver operating characteristics; AUC, area under the (ROC) curve; LBE, Lactate level pre-ECMO (mmol/l); LAE, Lactate level post-ECMO (mmol/l); L24 h, Lactate level $24 \mathrm{~h}$ after ECMO implantation; L48 h, Lactate level $48 \mathrm{~h}$ after ECMO implantation; LC-2, duration between ECMO implantation time and time point that Lactate cleared more than $10 \%$ of the initial level 


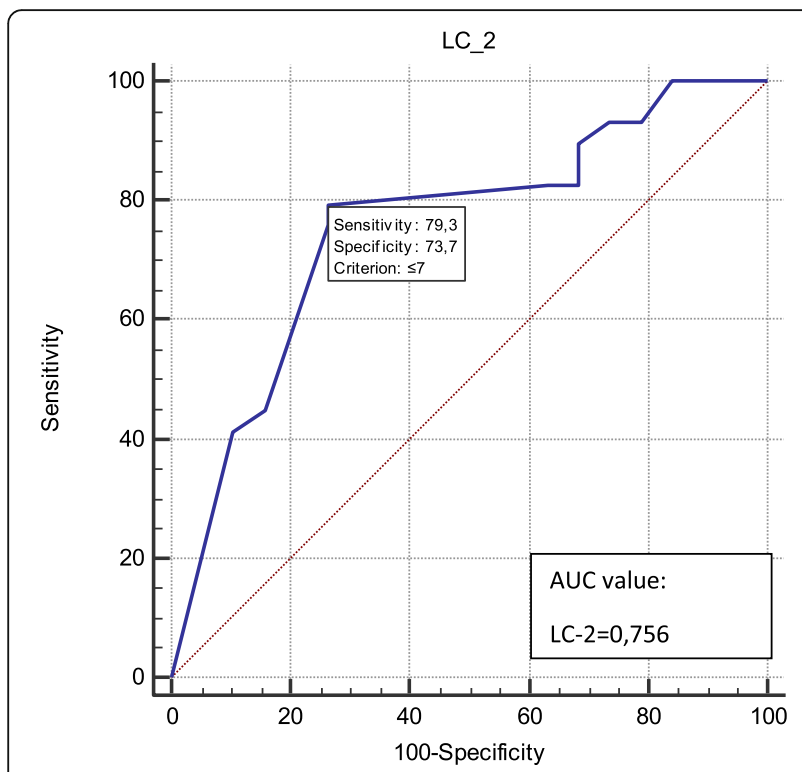

Fig. 4 ROC curve to demonstrate the predictive value of lactate clearance-2 on the length of stay in ICU more than 5 days. ROC, receiver operating characteristics; $A \cup C$, area under the (ROC) curve; LC-2, the duration between ECMO implantation time and time point that Lactate cleared more than $10 \%$ of the initial level

conclusions. Although different persons did data acquisition and statistical evaluation to overcome bias effect, one may hesitate about it.

\section{Conclusion}

A sufficient life support is a must for successful treatment of life-threatening situations and dynamic lactate indices empower evaluation of circulatory support by ECMO. Based on our results, an early insertion of ECMO before lactate gets high was suggested. Serial changes on lactate levels and calculation of its clearance may be superior to single lactate value on both effective circulatory support and as prognostic prediction marker. LC-2 showed a strong discrimination on 30-day mortality. Furthermore observing the course of blood lactate during ECMO therapy is a valuable tool not only for prediction of mortality but also for LOS in ICU.

\section{Abbreviations}

AUC: Area Under Curve; ECMO: Extracorporeal membrane oxygenation; eCPR: extracorporeal cardiopulmonary resuscitation; ICU: Intensive care unit; L48 h: Lactate level $48 \mathrm{~h}$ after ECMO implantation; LAE: Lactate level postECMO (mmol/l); LBE: Lactate level pre-ECMO ( $\mathrm{mmol} / \mathrm{l})$; LC-1: Lactate clearance-1; LC-2: Lactate clearance-2; LOS: Length of stay; LVAD: Left ventricular assist device; ROC: Receiver operating characteristic; $\mathrm{ScVO}_{2}$ : Central venous oxygen saturation; SD: Standard deviation; V-A ECMO: Veno-arterial-ECMO; V-V ECMO: Veno-venous ECMO

\section{Acknowledgements}

Not applicable.

\section{Funding}

No funding was received.

\section{Availability of data and materials}

The datasets during the current study available from the corresponding author on reasonable request.

\section{Disclosures}

None.

\section{Authors' contributions}

IM carried out the design of the study, Data collection \&/or processing, writing, performed the statistical analysis and drafted the manuscript. ŞB carried out the Literature search. DK participated in the sequence alignment. DA participated in the design of the study. ST conceived of the study, and participated in its design and coordination and helped to draft the manuscript. All authors read and approved the final manuscript.

\section{Ethics approval and consent to participate}

Since our study was in the category of non-interventional clinical research with its retrospective structure, the Ethical approval was not sought for the present study. This is in line with the National Code of Clinical Research which is recently published on 13th April 2013 [8].

This study adhered to the principles in accordance with the Helsinki Declaration of 1975, as revised in 2008.

A written informed consent was obtained either from the participants or their relatives before their admission to ICU as a routine procedure and in this informed consent, it is clearly stated that the data may be used in retrospective studies anonymously. An extra formal consent other than this consent was not required for the current study because of the noninterventional, retrospective design. It was a case-control medical record review.

\section{Consent for publication}

Not applicable.

\section{Competing interests}

The authors declare that they have no competing interests.

\section{Publisher's Note}

Springer Nature remains neutral with regard to jurisdictional claims in published maps and institutional affiliations.

Received: 14 May 2018 Accepted: 12 October 2018

Published online: 24 October 2018

\section{References}

1. Napp LC, Kühn C, Bauersachs J. ECMO in cardiac arrest and cardiogenic shock. Herz. 2017;42:27-44. https://doi.org/10.1007/s00059-016-4523-4.

2. Chen YS, Chao A, Yu HY, Ko WJ, Wu IH, Chen RJ, Huang SC, Lin FY, Wang SS. Analysis and results of prolonged resuscitation in cardiac arrest patients rescued by extracorporeal membrane oxygenation. J Am Coll Cardiol. 2003; $41(2): 197-203$. https://doi.org/10.1016/50735-1097(02)02716-X.

3. Guidelines for Adult Cardiac FailureVersion 1.3. Extracorporeal Life Support Organization (ELSO), 2013. Available online: https://www.elso.org/resources/ guidelines.aspx, https://www.elso.org/Portals/0/IGD/Archive/FileManager/ e76ef78eabcusersshyerdocumentselsoguidelinesforadultcardiacfailure1.3.pdf.

4. Levy MM. Preface biomarkers in critical illness. Crit Care Clin. 2011;27:xiii-xv. https://doi.org/10.1016/j.ccc.2011.01.001.

5. Li CL, Wang H, Jia M, Ma N, et al. The early dynamic behavior of lactate is linked to mortality in postcardiotomy patients with extracorporeal membrane oxygenation support: a retrospective observational study. J Thorac Cardiovasc Surg. 2015;149:1445-50. https://doi.org/10.1016/j.jtcvs. 2014.11.052.

6. Singh SP, Chauhan S, Bisoi AK, Sahoo M. Lactate clearance for initiating and weaning off extracorporeal membrane oxygenation in a child with regressed left ventricle after arterial switch operation. Ann Card Anaesth. 2016;19(1):188-91. https://doi.org/10.4103/0971-9784.173046.

7. Ryoo SM, Lee J, Lee YS, Lee JH, et al. Lactate level versus lactate clearance for predicting mortality in patients with septic shock defined by Sepsis-3. Crit Care Med. 2018;46(6):489-95. https://doi.org/10.1097/CCM. 0000000000003030 .

8. National Code on Clinical Researches published in Official Gazette numbered with 28030 at Apr 13, 2013. 
9. Kidney disease: improving global outcomes (KDIGO) acute kidney injury work group KDIGO clinical practice guideline for acute kidney injury. Kidney Int Suppl. 2012;2:1-138. https://doi.org/10.1038/kisup.2012.6.

10. Rastan AJ, Dege A, Mohr M, Doll N, et al. Early and late outcomes of 517 consecutive adult patients treated with extracorporeal membrane oxygenation for refractory postcardiotomy cardiogenic shock. J Thorac Cardiovasc Surg. 2010;139:302-11.

11. Attanà P, Lazzeri C, Picariello C, Dini CS, et al. Lactate and lactate clearance in acute cardiac care patients. Eur Heart J Acute Cardiovasc Care. 2012;1 (2): 115-21. https://doi.org/10.1177/2048872612451168.

12. Levraut J, Ichai C, Petit I, Ciebiera JP, et al. Low exogenous lactate clearance as an early predictor of mortality in normolactatemic critically ill septic patients. Crit Care Med. 2003;31(3):705-10.

13. Shalaby A, Khalafallah O, Galal M, Assal HH, et al. Correlation between serum lactate and other oxygenation indices as a predictor of outcome in respiratory ICU patients. Egypt J Chest Dis Tuberc. 2016;65(3):695-700. https://doi.org/10.1016/.jejcdt.2016.04.010

14. Attanà P, Lazzeri C, Chiostri M, Gensini GF, et al. Dynamic behavior of lactate values in venous-arterial extracorporeal membrane oxygenation for refractory cardiac arrest. Resuscitation. 2013;84:145-6.

Ready to submit your research? Choose BMC and benefit from:

- fast, convenient online submission

- thorough peer review by experienced researchers in your field

- rapid publication on acceptance

- support for research data, including large and complex data types

- gold Open Access which fosters wider collaboration and increased citations

- maximum visibility for your research: over $100 \mathrm{M}$ website views per year

At $\mathrm{BMC}$, research is always in progress.

Learn more biomedcentral.com/submissions 